\title{
EVANGÉLICOS, POLÍTICA E ESPAÇO: NOVAS ESTRATÉGIAS RUMO À PRESIDÊNCIA DA REPÚBLICA?
}

\author{
EVANGELICALS, POLITICS AND SPACE: NEW STRATEGIES FOR THE PRESIDENCY OF THE REPUBLIC?
}

\author{
Mônica Sampaio Machado ${ }^{1}$, Cristina Lontra Nacif ${ }^{2}$ \\ ${ }^{1}$ Universidade do Estado do Rio de Janeiro (UERJ), Rio de Janeiro, RJ, Brasil \\ ${ }^{1}$ Universidade Federal Fluminense (UFF), Rio de Janeiro, RJ, Brasil
}

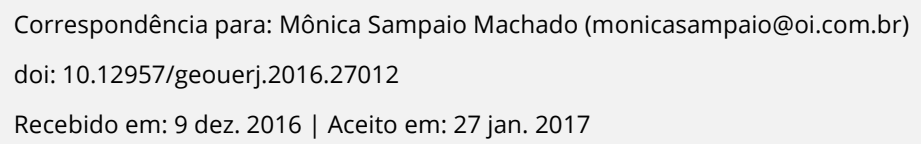

\section{RESUMO}

Este trabalho apresenta e discute o crescimento do segmento religioso evangélico no Brasil, principalmente pentecostal, e sua expressão na política e no espaço nacional. Os dados e informações que sustentam este estudo indicam não apenas o fortalecimento dos evangélicos na política, mas sobretudo novas estratégias que pressupõem a ampliação de suas bases, para além do campo religioso, ou estritamente evangélico. Vários segmentos evangélicos têm conseguido representações partidárias e parlamentares importantes nas diversas instâncias de poder, entre eles a Assembleia de Deus e a Igreja Universal do Reino de Deus. Juntos, eles formam um bloco coeso e forte, e cada vez mais conquistam espaços políticos no Executivo e no Legislativo. Para demonstrar essa situação, será primeiramente apresentada a expansão dos evangélicos no país entre os anos 2000-2010. Em seguida, será explicitada a representação política evangélica e as novas estratégias adotadas. Por último, o exemplo do Rio de Janeiro, que acabou de eleger como prefeito, pelo Partido Republicano Brasileiro e com apoio de vários segmentos evangélicos, Marcelo Crivella, da Igreja Universal. O Rio seria, então, um espaço estratégico para o setor evangélico e sua base de apoio rumo à presidência da República, em 2018 ?

Palavras-chave: Evangélicos, Expressão espacial, Política, Brasil e Rio de Janeiro.

\section{ABSTRACT}

This work presents and discusses the expansion of the evangelical religious segment in Brazil, mainly pentecostal, and its expression in politics and in the national space. The data and information that support this study indicate not only the strengthening of evangelicals in politics, but especially new strategies that presuppose the expansion of their bases, beyond the religious field, or strictly evangelical. Several evangelical segments have achieved important partisan and parliamentary representations in various power instances, among them the Assembleia de Deus and the Igreja Universal do Reino de Deus. Together, they form a cohesive and strong bloc, and increasingly gain political spaces in the Executive and Legislative. To demonstrate this situation, the expansion of evangelicals in the country between the years 2000-2010 will be presented first. Next, the evangelical political representation and the new strategies adopted will be made explicit. Finally, the example of Rio de Janeiro, just elected as mayor, by the Partido Rebublicano Brasileiro and with the support of various evangelical segments, Marcelo Crivella, of the Universal Church. Would Rio de Janeiro be a strategic space for the evangelical sector and its support base for the presidency of the Republic in 2018 ?

Keywords: Evangelicals, Space Expression, Politics, Brazil, Rio de Janeiro.

\section{INTRODUÇÃO}

Este trabalho apresenta e discute a ampliação do segmento religioso evangélico no Brasil, principalmente pentecostal, e sua expressão na política e no espaço nacional. Fruto de levantamentos e 
pesquisas realizadas pelo GeoBrasil, Grupo de Pesquisa Geografia Brasileira: História e Política, UERJ, os dados e informações que sustentam este estudo indicam não apenas o fortalecimento dos evangélicos na política, mas sobretudo uma nova tendência e novas estratégias que pressupõem a ampliação de suas bases em escala nacional e para além do campo religioso ou estritamente evangélico.

Utilizando de modernos meios de comunicação, associados às práticas sociais e territoriais ágeis e pragmáticas, e a um modelo de gestão empresarial de longo alcance, com investimentos diversificados, vários segmentos evangélicos têm conseguido representações partidárias e parlamentares importantes nas diversas instâncias poder, entre eles a Assembleia de Deus e a Igreja Universal do Reino de Deus. Juntos, eles formam um bloco coeso e forte, e cada vez mais conquistam espaços políticos no Executivo e no Legislativo de todo o país. A Assembleia de Deus, a igreja que mais cresce em número de fiéis em todo o Brasil, e a Universal do Reino de Deus, que contraditoriamente, perde adeptos, mas aumenta sua força e alcance político e espacial.

Para demonstrar essa situação, com base nos censos demográficos do IBGE, primeiramente será apresentado um panorama religioso do Brasil, um país que está se tornando cada vez menos católico. Registra-se a diminuição das porcentagens de católicos em todas as regiões brasileiras e, ao mesmo tempo, o aumento dos evangélicos, sobretudo dos pentecostais. Em seguida, serão exploradas as representações políticas evangélicas e as novas estratégias adotadas que ampliam sua força e expressão em escala nacional, a bancada e a frente evangélica. Por último, será trazido o exemplo do município do Rio de Janeiro, também gradativamente menos católico e mais evangélico, e que acabou de eleger como prefeito, pelo Partido Republicano Brasileiro, Marcelo Crivella, da Universal do Reino de Deus, igreja que, contraditoriamente, entre os anos 2000-2010, apresentou redução do número de adeptos no município. O exemplo do Rio vem assim indicar que o apoio recebido por Crivella das outras igrejas evangélicas foi fundamental, e consolidou seu papel de líder político não apenas da Universal, mas dos evangélicos. O Rio de Janeiro seria, então, um espaço estratégico para o setor evangélico e sua base de apoio rumo à presidência da República, em 2018 ? 


\section{Brasil, um país menos católico}

Apesar de o Brasil ainda seguir como o maior país católico do mundo, o aumento da população evangélica tem sido uma tendência desde meados do século XX. Segundo o último Censo Demográfico do IBGE, 2010, os católicos no Brasil representam 65\% da população, e os evangélicos, 22\% dela. 0 percentual de católicos vem diminuindo ROLIM, 1985. Censo Demográfico IBGE, 1980, 1991, 2000; no entanto, em contrapartida, o de evangélicos ampliando gradativamente. Em 1890, os evangélicos representavam 1\% da população total brasileira; em 1900, 1,1\%; em 1940, 2,6\%; em 1950, 3,4\%; em 1960, 4\%; em 1970; 5,2\%; em 1980, 6,6\%; em 1991, $12,25 \%{ }^{1}$; em 2000, 15,4\%; e em 2010, $22 \%{ }^{2}$.

$\mathrm{Na}$ atualidade, no caso brasileiro, os evangélicos estão subdivididos em várias igrejas ou denominações, que podem ser agrupadas em dois grupos mais expressivos: os históricos (para o IBGE, evangélicos de missão) e os pentecostais ${ }^{3}$. O grupo evangélico que mais cresceu é o pentecostal, com destaque para a Assembleia de Deus. A Igreja Universal do Reino de Deus (Iurd) tem mostrado sua força principalmente no campo político, conforme será apontado adiante. Segundo o Censo Demográfico do IBGE, 2010, os evangélicos somam 42.275.440, deste total 60\% são evangélicos pentecostais, ou seja, 25.370.484. Dos evangélicos pentecostais, 60\% são da Igreja Assembleia de Deus, ou seja, 12.314.410, e 7\% da Iurd, 1.873.243. Os dados que podem ser observados nas tabelas 1 e 2 , a seguir.

A tabela 1 mostra, no período compreendido entre os anos 2000-2010, a percentagem de católicos, evangélicos, evangélicos pentecostais, evangélicos de missão e espíritas no Brasil e nas Grandes Regiões. A tabela 2 apresenta, no mesmo período, em números absolutos a população católica, evangélica, evangélica pentecostal, Iurd e Assembleia da Deus, no Brasil e nas Grandes Regiões, assim como o percentual total dessas religiões no Brasil e sua expressão nas Grandes Regiões.

\footnotetext{
${ }^{1}$ ROLIM, 1985. Censo Demográfico IBGE, 1980, 1991, 2000.

${ }^{2}$ Censo Demográfico IBGE, 2010. (http://www.sidra.ibge.gov.br/cd/cd2010CGP.asp?o=13\&i=P)

${ }^{3}$ Para um panorama e discussão sobre os evangélicos no Brasil, ver ROLIM, 1985; MACHADO, 1993 e 2009 ; MACHADO e NACIF, 2004; MAFRA, 2001.
} 


\begin{tabular}{c|c|c|c|c|c|c|c|c|c|c}
\hline & \multicolumn{2}{|c|}{ Católicos } & \multicolumn{2}{c|}{ Evangélicos } & \multicolumn{2}{c}{$\begin{array}{c}\text { Evangélicos } \\
\text { pentecostais }\end{array}$} & $\begin{array}{c}\text { Evangélicos de } \\
\text { missão }\end{array}$ & \multicolumn{2}{c}{ Espíritas } \\
\hline & $\mathbf{2 0 0 0}$ & $\mathbf{2 0 1 0}$ & $\mathbf{2 0 0 0}$ & $\mathbf{2 0 1 0}$ & $\mathbf{2 0 0 0}$ & $\mathbf{2 0 1 0}$ & $\mathbf{2 0 0 0}$ & $\mathbf{2 0 1 0}$ & $\mathbf{2 0 0 0}$ & $\mathbf{2 0 1 0}$ \\
\hline Brasil & 73,57 & 64,63 & 15,41 & 22,16 & 10,37 & 13,30 & 4,09 & 4,03 & 1,33 & 2,02 \\
\hline Norte & 71,27 & 60,61 & 19,75 & 28,50 & 14,35 & 20,09 & 4,32 & 4,81 & 0,38 & 0,49 \\
\hline Nordeste & 79,93 & 72,19 & 10,26 & 16,39 & 6,89 & 10,08 & 2,87 & 3,45 & 0,56 & 0,83 \\
\hline Sudeste & 69,17 & 59,46 & 17,51 & 24,58 & 12,05 & 14,32 & 4,28 & 3,93 & 1,98 & 3,06 \\
\hline Sul & 77,41 & 70,09 & 15,33 & 20,18 & 8,73 & 10,91 & 5,67 & 4,96 & 1,16 & 2,01 \\
\hline Centro-0este & 69,12 & 59,55 & 18,87 & 26,82 & 13,38 & 16,64 & 4,17 & 4,10 & 1,88 & 2,29 \\
\hline
\end{tabular}

Tabela 1. Percentagem de católicos, evangélicos, evangélicos pentecostais, evangélicos de missão e espíritas,

Brasil e Grandes Regiões, 2000-2010. Fonte: Censo Demográfico IBGE, 2000-2010

\begin{tabular}{|c|c|c|c|c|c|c|c|c|c|c|c|}
\hline & Pop. total & Católica & $\%$ & Evangélica & $\%$ & $\begin{array}{l}\text { Evangélica } \\
\text { pentecostal }\end{array}$ & $\%$ & IURD & $\%$ & $\begin{array}{c}\text { Assembleia } \\
\text { de Deus }\end{array}$ & $\%$ \\
\hline Brasil & 190.755 .799 & 123.280 .172 & 65 & 42.275 .440 & 22 & 25.370 .484 & 13 & 1.873 .243 & 1 & 12.314 .410 & 6 \\
\hline Norte & 15.864 .454 & 9.614 .913 & 5 & 4.521 .971 & 2 & 3.187 .100 & 1,7 & 204.997 & 0,1 & 1.929 .330 & 1 \\
\hline Nordeste & 53.081 .950 & 38.317 .276 & 20 & 8.698 .480 & 5 & 5.348 .024 & 2,8 & 439.455 & 0,2 & 3.364 .414 & 1,7 \\
\hline Sudeste & 80.364 .410 & 47.781 .673 & 25 & 19.756 .522 & 10 & 11.508 .725 & 6 & 897.870 & 0,5 & 4.608 .078 & 2,4 \\
\hline Sul & 27.386 .891 & 19.194 .403 & 10 & 5.527 .796 & 3 & 2.986 .790 & 1,6 & 171.989 & 0,1 & 1.235 .909 & 0,7 \\
\hline Centro-Oeste & 14.058 .094 & 8.371 .908 & 4 & 3.770 .671 & 2 & 2.339 .845 & 1,2 & 158.932 & 0,1 & 1.176 .679 & 0,6 \\
\hline
\end{tabular}

Tabela 2. População total e percentual de adeptos à religião católica, evangélica, evangélica pentecostal, Iurd e Assembleia de Deus, Brasil e Grandes Regiões, 2010. Fonte: Censo Demográfico IBGE, 2000-2010 


\section{Os evangélicos e suas novas representações e estratégias políticas: bancadas evangélicas e a Frente Parlamentar Evangélica}

Com o crescimento do número de evangélicos, a participação desse segmento religioso no cenário político brasileiro se tornou expressiva. No final do século XX, vários evangélicos foram eleitos para diferentes níveis de governo. Essa visibilidade na esfera pública dos evangélicos ocorreu em finais da década de 1990, impulsionada, principalmente, pelo segmento pentecostal, que modernizou a forma de comunicação e passou a expressar sua mensagem religiosa utilizando, progressivamente, os meios de comunicação; inicialmente, o rádio e a televisão, e posteriormente, as mídias eletrônicas.

A primeira bancada evangélica no Congresso Nacional foi registrada na composição da Nova Constituinte, em 1986, momento em que ocorria a distribuição de emissoras de rádio e TV em troca de favorecimentos para o governo pemedebista de José Sarney (CUNHA, 2016) ${ }^{4}$. Desde então, a bancada evangélica tem se ampliado e suas posições estão ganhando cada vez mais espaço, não apenas no Legislativo nacional, mas também estadual e municipal, a ponto de ter conseguido montar uma Frente Parlamentar Evangélica do Congresso Nacional em 2003, conforme será comentado adiante ${ }^{5}$. Para se ter uma ideia desse crescimento, segundo dados do Departamento Intersindical de Assessoria Parlamentar (Diap), nas eleições de 2006 a bancada evangélica no Congresso Nacional contava com 36 representantes. Destes, 34 foram reconduzidos em 2010, e 39 novos parlamentares evangélicos foram eleitos.

\footnotetext{
${ }^{4}$ Bancada é a denominação dada a grupos suprapartidários compostos de políticos dos poderes legislativos federal, estadual e municipal que atuam e defendem interesses comuns. São grupos de interesses que se articulam para defesa de projetos e ideais comuns, independentes de suas filiações e compromissos partidários. Embora a bancada evangélica seja constituída principalmente por políticos pertencentes às igrejas pentecostais, ela expressa e defende os interesses das igrejas evangélicas, sejam igrejas evangélicas de missão (tradicionais) ou pentecostais.

${ }^{5}$ A Frente Parlamentar Evangélica, grupo cristão suprapartidário e numerosamente maior, inclui, além de políticos evangélicos, vários outros não filiados a nenhuma igreja evangélica, mas que expressam e defendem um sistema de valores ideológicos e religiosos semelhantes, pautados por interesses corporativos e conservadores. A Câmara dos Deputados criou o registro de Frentes Parlamentares em 2005 e considerou Frente Parlamentar a associação suprapartidária de pelo menos um terço de membros do Poder Legislativo Federal, destinada a promover o aprimoramento da legislação federal sobre determinado setor da sociedade. (Câmara dos Deputados http://www2.camara.leg.br/legin/int/atomes/2005/atodamesa-69-10-novembro-2005-539350-publicacaooriginal37793-cd-mesa.html). Acesso em 18 de junho de 2016.
} 
Assim, a bancada evangélica, em 2010, passou a contar com 73 representantes, 70 deputados federais e três senadores evangélicos. ${ }^{6}$ Em 2014, essa bancada passou a ser composta por 87 deputados federais e três senadores (Magno Malta, do PR, da Igreja Batista, eleito pelo estado do Espírito Santo, Marcelo Crivella, do PRB, da Iurd, eleito pelo Rio de Janeiro, e Walter Pinheiro, da Igreja Baptista, então do PT, eleito pela Bahia), totalizando 90 parlamentares. $^{7}$ O Partido Republicano Brasileiro (PRP) é o partido mais forte da bancada evangélica. Destacam-se também o DEM, o PMDB e o PSD. Com relação à filiação religiosa, cerca de 10\% fazem parte da igreja presbiteriana, 20\% estão distribuídos em diversas denominações, sendo mais da metade pertencente à Assembleia de Deus, à Iurd e à Igreja Batista. A Assembleia de Deus apresenta o maior número de políticos, seguida pela Iurd e pela Igreja Batista. Assim, entre as igrejas evangélicas com maior expressão política, duas igrejas pentecostais passaram a se destacar: a Assembleia de Deus e a Igreja Universal do Reino de Deus (Iurd).

A Assembleia de Deus foi a segunda igreja evangélica pentecostal a surgir no Brasil, resultante da dissidência de evangélicos batistas, em 1911, em Belém do Pará. Hoje com maior número de adeptos aproximadamente 12 milhões -, vem apresentando uma importante taxa de crescimento, conforme pode ser conferido na Tabela 3. A Iurd nasceu da iniciativa de Edir Macedo, grande empresário do mercado religioso, no subúrbio da cidade do Rio de Janeiro, em 1977. Embora não seja a Igreja mais expressiva em número de fiéis, e tenha apresentado redução entre os anos 2000-2010, sua atuação no campo da política merece destaque. É interessante observar, na tabela 3, que a Universal tem mantido a percentagem de fiéis na Região Nordeste, historicamente católica, e ampliado na Região Norte. Já a Assembleia aumentou a percentagem de fiéis em todas as regiões, com destaque para as regiões Norte e Centro-Oeste, justamente as que têm apresentado o percentual de evangélicos maior que a média nacional, como pode ser conferido no figura1.

\footnotetext{
${ }^{6}$ DIAP - http://www.diap.org.br/index.php?option=com_content\&view=article\&id=14637-evangelicos-crescem-nocongresso-psc-lidera-em-numero-de-parlamentares. Acesso em 10 de maio de 2016.

${ }^{7}$ Grupo de Pesquisa Mídia, Religião e Política. http://www.metodista.br/midiareligiaopolitica/index.php/composicaobancada-evangelica/ Acesso em 10 de setembro de 2016.
} 


\begin{tabular}{c|c|c|c|c|c|c|c|c}
\cline { 2 - 9 } & \multicolumn{4}{c|}{ Assembleia de Deus } & \multicolumn{3}{c}{ Universal do Reino de Deus } \\
& $\mathbf{2 0 0 0}$ & $\%$ & $\mathbf{2 0 1 0}$ & $\%$ & $\mathbf{2 0 0 0}$ & & $\mathbf{2 0 1 0}$ & $\%$ \\
\hline Brasil & 8.418 .140 & 5,0 & 12.314 .410 & 6,5 & 2.101 .887 & 1,24 & 1.873 .243 & 1,0 \\
\hline Norte & 1.289 .002 & 10,0 & 1.929 .330 & 12,2 & 157.317 & 1,2 & 204.997 & 1,3 \\
\hline Nordeste & 2.222 .783 & 5,0 & 3.364 .414 & 6,3 & 381.851 & 0,8 & 439.455 & 0,8 \\
\hline Sudeste & 3.213 .805 & 4,5 & 4.608 .078 & 5,7 & 1.185 .916 & 1,6 & 897.870 & 1,1 \\
\hline Sul & 902.933 & 3,6 & 1.235 .909 & 4,5 & 211.441 & 0,8 & 171.989 & 0,6 \\
\hline Centro-0este & 789.618 & 6,8 & 1.176 .679 & 8,4 & 165.361 & 1,4 & 158.932 & 1,1 \\
\hline
\end{tabular}

Tabela 3. Números absolutos e relativos de fiéis da Assembleia de Deus e Iurd, 2000-2010. Fonte: Censo Demográfico IBGE, 2000-2010

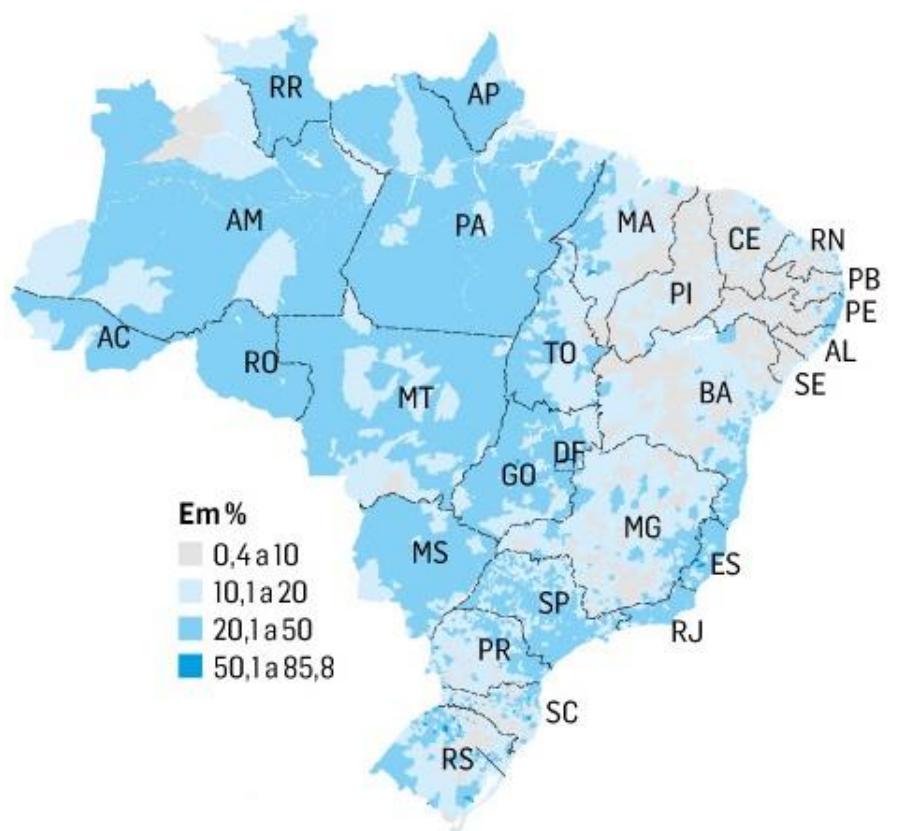

Figura 1. Percentagens de Evangélicos no Brasil, 2010. Fonte: IBGE, 2010. http://estadaodados.com/religiao. Acesso em 30/11/2016.

Essa força política evangélica foi consolidada com a composição da Frente Parlamentar Evangélica do Congresso Nacional, criada em 2003 e formalizada em 2005, e com eleição da última diretoria para 
2015-2019, em fevereiro de 2015. ${ }^{8}$ Ao analisarmos a Frente Parlamentar Evangélica em novembro de 2016, da 55ª Legislatura (2015-2018), chama atenção o aumento do número de representantes. Embora de matriz cristã, nem todos os parlamentares têm ligação direta com as igrejas evangélicas; há também católicos praticantes, católicos carismáticos e deputados eleitos com apoio de igrejas evangélicas, mas não a elas vinculados. Segundo o site da Câmara dos Deputados, compõem a FPE 199 deputados e quatro senadores, quais sejam: Flexa Ribeiro, do PSDB Pará, Magno Malta, do PR, da Igreja Batista, Walter Pinheiro, atualmente sem partido, da Igreja Baptista, e Marcelo Crivella, do PRB, da Iurd, sendo esses dois últimos licenciados. Crivella foi eleito para a Prefeitura do Rio de Janeiro e Walter Pinheiro assumiu a Secretaria de Estado da Bahia. ${ }^{9}$ Os dois esquemas expostos a seguir foram montados pela Agência Pública e apresentam as Frentes da Câmara dos Deputados, em 2016. No figura 2 é destacada a composição da Frente Parlamentar Evangélica e, no figura 3, sua articulação com outras frentes.

Deputados, em 2016. No figura 2 é destacada a composição da Frente Parlamentar Evangélica e, no figura 3 , sua articulação com outras frentes. ${ }^{10}$

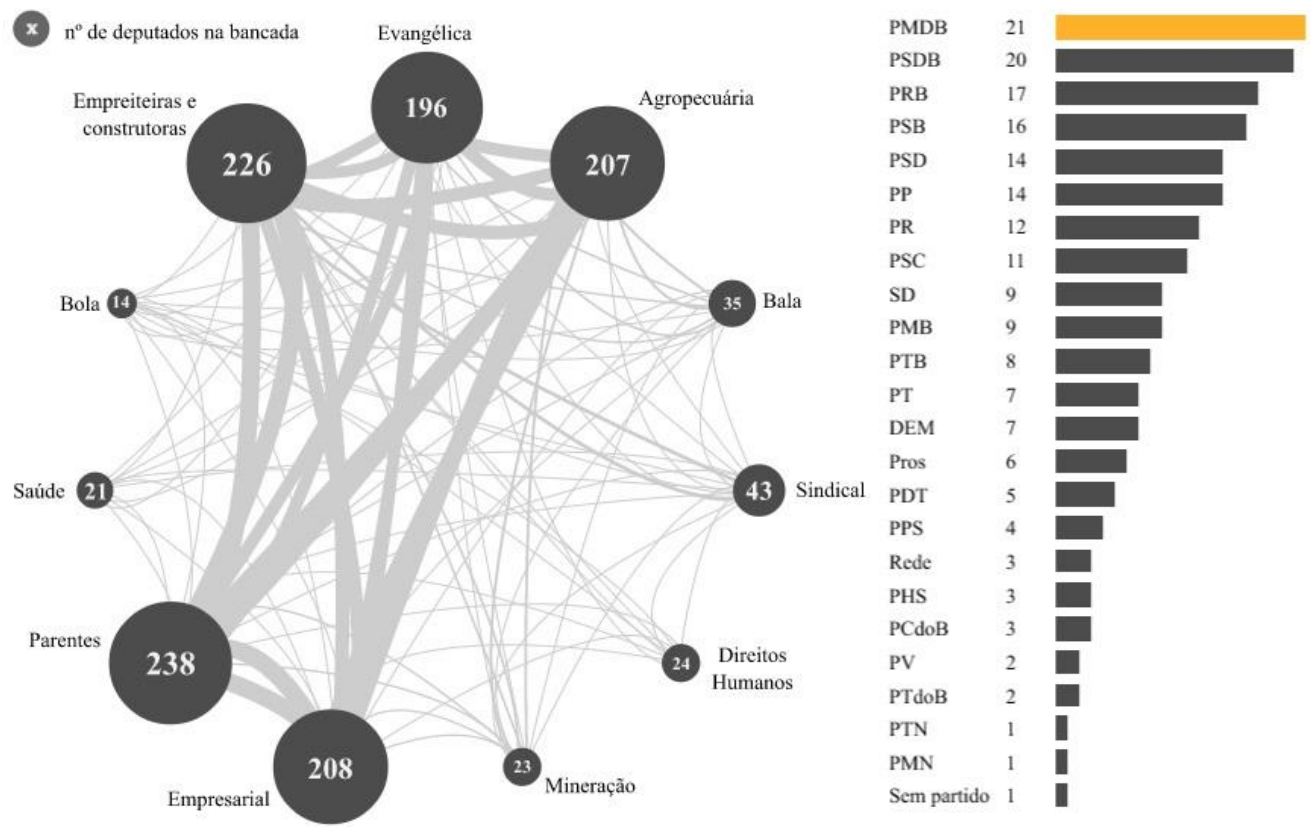

\footnotetext{
${ }^{8}$ Câmara dos Deputados - http://www.camara.leg.br/internet/deputado/Frente_Parlamentar/53658-integra.pdf, Ata de Eleição da Frente Parlamentar Evangélica do Congresso Nacional, 2015.

${ }^{9}$ Câmara dos Deputados - http://www.camara.leg.br/internet/deputado/frenteDetalhe.asp?id=53658. Acesso em 11 de novembro de 2016.

${ }^{10}$ O total de parlamentares da figura compreende 196, e não 199, em função de não terem sido aqui considerados os parlamentares afastados.
} 
Figura 2. Frentes da Câmara dos Deputados, Frente Parlamentar Evangélica e sua composição partidária, 2016. Fonte: Agência Pública, 2016. http://apublica.org/2016/02/truco-as-bancadas-da-camara/

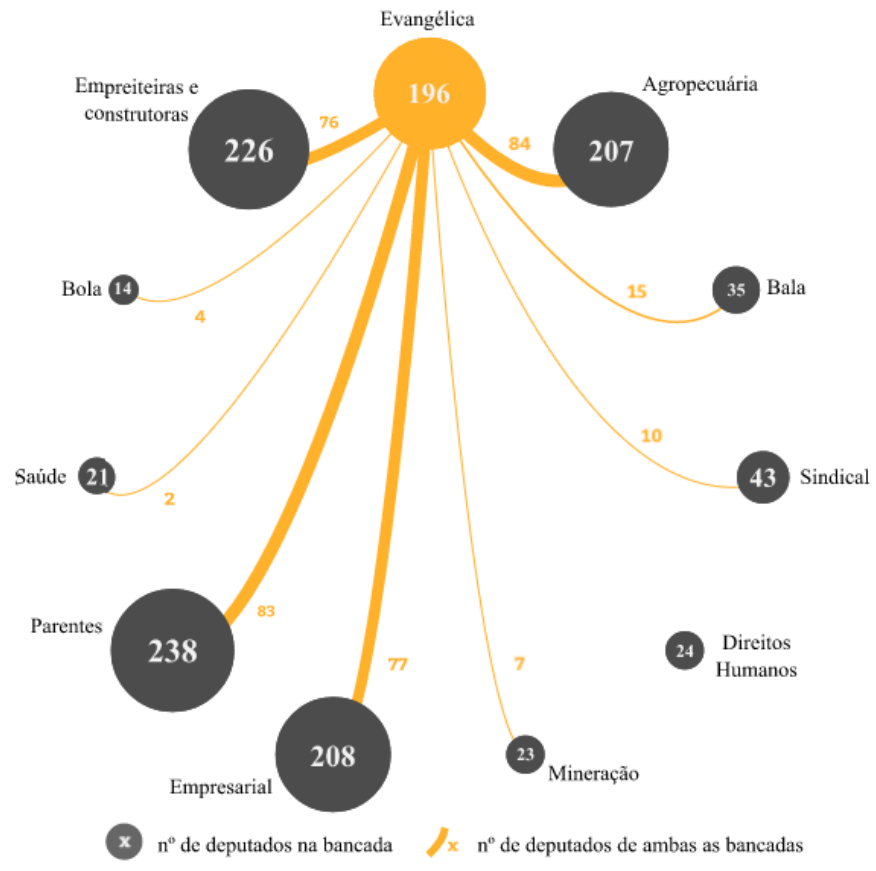

Figura 3. Articulação das Frentes da Câmara dos Deputados, 2016.Fonte: Agência Pública, 2016. http://apublica.org/2016/02/truco-as-bancadas-da-camara/

Como pode ser observado, o PMDB, o PSDB e o PRB são os partidos que mais possuem representantes na Frente Parlamentar Evangélica, com 21, 20 e 17 políticos, respectivamente. Destes, destaca-se o Partido Republicano Brasileiro, PRB, pela expressão política alcançada em tão pouco tempo de existência. Aqui, vale mencionar a participação e articulação não apenas dos evangélicos, mas sobretudo da Iurd, na sua criação. O PRB foi registrado em 2005, inicialmente com a denominação de Partido Municipalista Renovador. Como primeiros filiados, entre outros, o PRB contou, na época, com o então vice-presidente da República José Alencar, que era católico, e o Ministro de Assuntos Estratégicos Roberto Mangabeira Unger, naquele momento vice-presidente do PRB, e o então senador bispo da Iurd Marcelo Crivella. ${ }^{11}$ Segundo dados do Tribunal Superior Eleitoral, em 2005, o PRB tinha 3.295 eleitores filiados; em 2008, 177.689; em 2012, 289.457; e em 2016,

\footnotetext{
${ }^{11}$ José Alencar se filiou ao PMR no dia 29 de setembro de 2005, ao lado do Senador Marcelo Crivella. À época, o partido ainda se chamava Partido Municipalista Renovador e passaria a se chamar PRB na próxima convenção partidária, por sugestão do próprio José Alencar.
} 
389.434. Atualmente conta com 1.627 vereadores, 104 prefeitos, 38 deputados estaduais, 22 deputados federais, um senador e um ministro. ${ }^{12}$

Ao analisarmos a expressão dos eleitores do Partido em termos regionais, destaca-se a Região Nordeste, seguida da Sudeste e Norte, conforme pode ser conferido na tabela 4, a seguir.

\begin{tabular}{|l|r|r}
\hline & \multicolumn{1}{c|}{ total } & \multicolumn{1}{c}{$\%$} \\
\hline Brasil & 289.457 & 100 \\
\hline Norte & 55.803 & 19 \\
\hline Nordeste & 94.434 & 33 \\
\hline Sudeste & 69.522 & 24 \\
\hline Sul & 34.742 & 12 \\
\hline Centro-Oeste & 34.956 & 12 \\
\hline
\end{tabular}

Tabela 4. Número total e percentual de eleitores filiados ao Partido Republicano Brasileiro, Brasil e Grandes Regiões, 2012. Fonte: Tribunal Superior eleitoral. ${ }^{13}$

Embora o PRB não seja um partido da Igreja Universal, a ela se associa e tem forte participação. Para ilustrar a expressão da Iurd no PRB, vale mencionar que o Partido tem atualmente, como líder da Executiva Nacional, o ex-ministro da Pesca e Agricultura do Governo Dilma, em 2014, Eduardo Lopes, membro da Igreja Universal. Lopes exerceu importantes cargos nos empreendimentos da Iurd, na Rede Record, no Jornal Folha Universal e na Editora Gráfica Universal. Eduardo Lopes está substituindo o bispo licenciado da Iurd, o advogado Marcos Pereira, que atualmente ocupa o cargo de Ministro de Estado do Desenvolvimento, Indústria e Comércio do atual Governo de Michel Temer. Marcos Pereira é homem de confiança de Edir Macedo - foi diretor administrativo e financeiro da TV Record-Rio de Janeiro e vice-presidente da Rede Record de Televisão. ${ }^{14}$

\footnotetext{
12 Tribunal Superior Eleitoral - http://www.tse.jus.br/eleitor/estatisticas-de-eleitorado/filiados. Acesso em 30 outubro de 2016.

${ }^{13}$ Tribunal Superior Eleitoral - http://www.tse.jus.br/eleitor/estatisticas-de-eleitorado/filiados. Acesso em 30 de outubro 2016.

${ }^{14}$ El País, 3 de junho de 2016. http://brasil.elpais.com/brasil/2016/06/08/opinion/1465385098_545583.html?rel=mas. Acesso 8 de agosto de 2016. Em 2012, pelo menos 66\% das lideranças do PRB tinham ou já haviam tido ligações com a lurd. E quando considerado o envolvimento com o grupo Record, o número sobe para $73 \%$. Essa ligação foi chamada pelo cientista político e professor da Fundação Getúlio Vargas (FGV-SP) Claudio Gonçalves Couto de "empreendimento". Ou seja, Igreja, Record e PRB fazem parte do mesmo conglomerado com forte influência geográfica. Terra, 20 de setembro de 2012 https://noticias.terra.com.br/amp/brasil/politica/prb-de-russomanno-tem-
} 
Não obstante essa força da Universal, atualmente observa-se uma tendência dentro do Partido de buscar uma articulação com outras igrejas evangélicas, com o objetivo de eleger outros representantes do meio protestante em geral e ganhar espaço na política. Apesar dessa iniciativa, a Igreja da Assembleia de Deus tem buscado construir sua própria estratégia política. Ao perceber a força política e partidária da Iurd, passou a se unir ao Partido Social Cristão (PSC), de onde saíram os pastores Marco Feliciano e Everaldo. A Assembleia hoje tem o intuito de formar um partido próprio, e parece estar em vias de ser fundado o Partido Republicano Cristão (PRC) ${ }^{15}$.

Como pode ser percebido os evangélicos passaram a atuar de forma muito direta e objetiva na esfera política. Essa ampliação da articulação e força política evangélica é nova no cenário nacional e está alcançando escalas jamais vistas.

Até 2010, as pautas evangélicas eram muito domésticas, paroquiais. Eram projetos para dar destaque a uma igreja, ou a um pastor, ou a um assunto da agenda dos evangélicos, mas disputando atenção nesse universo pequeno, o Dia da Igreja X ou Y, voltado ao universo religioso e doméstico. No entanto, a perspectiva da força dos grupos que cresciam ao longo dos anos 1980 e 1990 já vinha tomando corpo. Qual era o cenário? O crescimento da população evangélica, a novidade e a força da palavra do pastor, e aí alguns políticos aproveitam essas forças para se aproximar de uma parcela do eleitorado, uma parcela importante. A palavra do pastor certamente valia um voto. Por isso a perspectiva estava lá. (CUNHA, 2016). ${ }^{16}$

Essa expressão política evangélica congrega não apenas fiéis evangélicos, mas também os que compartilham dos mesmos ideais e projetos, em sua maioria conservadores, como pode ser averiguado nos posicionamentos dos deputados da Frente Parlamentar Evangélica. Os pontos de defesa dessa Frente são reveladores nesse sentido: são contrários, por exemplo, à igualdade de gênero, ao direito ao aborto, à eutanásia, ao casamento entre pessoas do mesmo sexo, à manutenção da idade penal em 18 anos, entre outros. Foi justamente essa mesma força política que teve papel destacado sobre a

66-dos-dirigentes-ligados-a-universal,9cb99782ac66b310VgnCLD200000bbcceb0aRCRD.html. Acesso em 20 de outubro de 2016.

${ }^{15}$ Revista Giz. http://revistagiz.sinprosp.org.br/?p=6531. Acesso em 30 de outubro de 2016.

${ }^{16}$ SILVA, Magali. Entrevista de Magali Silva concedida a Elisa Marconi e Francisco Bicudo para a Revista Giz, 2016. (http://revistagiz.sinprosp.org.br/?p=6531). Acesso em 25 de junho de 2016. 
admissibilidade do pedido do impeachment da presidenta Dilma Rousseff. Segundo a Agência Pública, a maior rejeição à petista adveio da Frente Evangélica, da Agropecuária, da Bala e da Empresarial. Em ordem decrescente, votaram pelo impeachment as Frentes da Bala (88,24\%), Empresarial (85,32\%), Evangélica (83,85\%), Ruralista (82,93\%), Mineração (79,12\%) e Parentes (74,49\%), esta última formada por deputados com familiares na política. Em números absolutos, o apoio dos parlamentares da Bancada Empresarial foi o mais expressivo, com o voto "sim" de 186 dos seus 218 integrantes. Em seguida está a Frente dos Parentes, que registrou o apoio de 181 dos 243 integrantes. Entre os ruralistas, que somam 205 deputados, foram 170 manifestações favoráveis ao parecer do relator, enquanto o impedimento da presidenta foi apoiado por 161 dos 192 da Frente Evangélica. ${ }^{17}$

Contudo, vale a pena assinalar que a atuação política dos evangélicos está também sustentada por uma forma de agir muito pragmática. Mesmo tendo votado a favor do impedimento de Dilma Rousseff, os evangélicos e o PRB apoiaram e fizeram parte do Governo Dilma e Lula, como indicado anteriormente, posicionamento que seria impensável para um partido como o PSDB. Outro exemplo desse pragmatismo e que também demonstra sua força política foi a inauguração do Templo de Salomão, em 2014, a nova sede mundial da Igreja Universal do Reino de Deus, construída no Brás, em São Paulo. O Templo se tornou o maior espaço religioso do país, com 100 mil metros quadrados e capacidade para 10 mil pessoas. Na inauguração, estiveram presentes as maiores autoridades dos três poderes no país daquele momento: Dilma Rousseff e Michel Temer (Presidente e Vice-presidente da República); Geraldo Alckmin (Governador de São Paulo); Fernando Haddad (Prefeito de São Paulo); Marco Aurélio Mello (Ministro do STF); Elizabeth Teixeira Rocha (Presidente do STM); Leandro Daiello Coimbra (Diretor da Polícia Federal); o Cônsul-Geral de Israel, Yoel Barnea; além de diversos governadores, deputados federais e estaduais, vereadores e prefeitos. ${ }^{18}$

O Jornal El País chega a afirma que

\footnotetext{
${ }^{17}$ Agência Pública - http://apublica.org/2016/02/truco-as-bancadas-da-camara/. Acesso em 30 de outubro de 2016. ${ }^{18}$ Noticias R7. 31 de julho de 2014. http://noticias.r7.com/brasil/com-a-presenca-de-dilma-templo-de-salomao-einaugurado-em-sao-paulo-13102016, Acesso em 30 de agosto de 2016.
} 
O PT flertou com os evangélicos ao longo dos mandatos do ex-presidente Luiz Inácio Lula da Silva e da presidente afastada Dilma Rousseff. Não fosse o engajamento de pastores e bispos das igrejas pentecostais, provavelmente o partido não teria ganhado quatro eleições seguidas. E para garantir esse apoio, os petistas abriram mão de compromissos históricos, principalmente aqueles relacionados à luta pelos direitos das minorias (mulheres, homossexuais, negros e índios), concentrando esforços na melhoria das condições de vida da população pobre, também público-alvo dos pentecostais. De qualquer maneira, os governos Lula e Dilma, ainda que reféns dos evangélicos, mantiveram uma agenda propositiva no campo social. ${ }^{19}$

\section{O exemplo do Rio de Janeiro: Crivella, do PRB, é eleito prefeito}

O município do Rio de Janeiro tem apresentado um declínio do número de católicos e o crescimento de evangélicos, principalmente do seguimento pentecostal. Embora a Igreja Universal do Reino de Deus venha fortalecendo sua expressão política, contraditoriamente, tem apontado um declínio do número de fiéis no município, entre os anos 2000-2010, conforme dados do Censo Demográfico do IBGE, como pode ser conferido na tabela 5. Não obstante, o candidato eleito para a Prefeitura carioca foi um importante representante da Iurd, Marcelo Crivella. ${ }^{20}$

\begin{tabular}{|c|c|c|c|c}
\cline { 2 - 5 } & \multicolumn{4}{|c}{ Município do Rio de Janeiro } \\
& $\mathbf{2 0 0 0}$ & $\%$ & $\mathbf{2 0 1 0}$ & $\%$ \\
\hline População total & 5.857 .904 & 100 & 6.320 .446 & 100 \\
\hline Católicos & 3.556 .096 & 60,71 & 3.229 .192 & 51,09 \\
\hline Evangélicos & 1.034 .009 & 17,65 & 1.477 .021 & 23,37 \\
\hline Pentecostais & 643.726 & 10,99 & 794.006 & 12,56 \\
\hline
\end{tabular}

\footnotetext{
${ }^{19}$ El País, 3 de junho de 2016. http://brasil.elpais.com/brasil/2016/06/08/opinion/1465385098_545583.html?rel=mas. Acesso 8 de agosto de 2016.

${ }^{20}$ Crivella ingressou na carreira política em 2002, quando foi eleito senador do Rio de Janeiro, com 3,5 milhões de votos. No Congresso Nacional, foi vice-líder do Governo Lula e líder da bancada do Partido Liberal. Em 2005, fundou com o vice-presidente da República, José Alencar Gomes da Silva, o PRB, do qual foi seu líder no Senado desde então. Foi reeleito em 2010 para um mandato de 2011 a 2019. Assumiu o Ministério da Pesca e Aquicultura no governo de Dilma Rousseff, em 2012. Deixou a pasta em 2014, para concorrer ao cargo de governador do Rio de Janeiro, ao qual já havia concorrido em 2006. Candidatou-se ainda à Prefeitura do Rio de Janeiro em 2004, 2008 e 2016, quando foi eleito, tornando-se o 53 prefeito da cidade.
} 


\begin{tabular}{|c|c|c|c|c}
\hline Assembleia de Deus & 303.257 & 5,18 & 432.138 & 6,84 \\
\hline Universal (Iurd) & 179.314 & 3,06 & 116.906 & 1,85 \\
\hline
\end{tabular}

Tabela 5. População total, católicos, evangélicos, evangélicos pentecostais, Assembleia de Deus e Iurd, município do Rio de Janeiro, 2000-2010. Fonte: Censo Demográfico IBGE, 2000-2010

Além do vitorioso Marcelo Crivella, no plano do Legislativo municipal do Rio, em 2016, o PRB, partido do prefeito eleito, abrigará três vereadores: João Mendes de Jesus (reeleito), Tânia Cristina Magalhães Bastos e Silva (reeleita) e José Inaldo Fernandes da Silva, todos os três da Igreja Universal do Reino de Deus (Iurd). ${ }^{21}$ Mas, se a bancada evangélica contava, no período de 2012 2016, com seis vereadores - Jorge Manaia (SD), Eliseu Kessler da Assembleia de Deus (PSD), João Mendes de Jesus (PRB), Jorge Braz (PRB), Tania Bastos (PRB) e Alexandre Isquierdo da Assembleia de Deus $(\mathrm{DEM})^{22}$-, a expectativa agora é sua ampliação, que provavelmente receberá apoio de uma das maiores bancadas eleitas, a do PMDB, e de vereados de partidos que se declararam independentes, como o DEM, o PSDB e o PSC, que elegeu o vereador mais votado na Câmara, Carlos Bolsonaro.

A importância das bases políticas evangélicas nas eleições para prefeito na cidade do Rio de Janeiro vem sendo destacada desde o ano 2000. Não foi por acaso que o jornal A Folha de São Paulo ${ }^{23}$ anunciou que a disputa para a Prefeitura carioca, em 2004, estava dividida entre o Pan, uma das grandes promessas de César Maia, e os evangélicos, cujo candidato foi o bispo Crivella. Na época, os votos recebidos por Crivella já apresentavam uma tendência de distribuição espacial na cidade, confirmada agora nas eleições à Prefeitura do Rio, 2016. Em 2004 puderam ser identificadas algumas faixas percentuais de seus eleitores: a mais baixa nos bairros da zona sul e as mais expressivas nos bairros da zona oeste, em primeiro plano, e, em seguida, nos bairros da zona norte. Na tentativa de

\footnotetext{
${ }^{21}$ João Mendes de Jesus é economista e pastor, foi eleito Deputado Federal para a legislatura entre 2003 e 2007. Convertido em 1981, participou de seminário interno de caráter teológico, sob a direção do bispo Edir Macedo, no ano de 1982. Tornou-se pastor em 1986 e foi consagrado bispo em 1996. Tânia Cristina Magalhães Bastos e Silva é pedagoga, e José Inaldo Fernandes da Silva é bispo e tem ensino fundamental incompleto. (Câmara Municipal do Rio de Janeiro - http://www.camara.rj.gov.br). Acesso em 30 de outubro de 2016.

${ }^{22}$ Câmara Municipal do Rio de Janeiro - http://www.camara.rj.gov.br/. Acesso em 30 de outubro de 2016

${ }^{23}$ Dia 20 de setembro de 2004.
} 
interpretar esses resultados, interessante análise foi feita por Israel Tabak, no Jornal do Brasil, logo após as eleições de 2004, com base em informações de pesquisadores da PUC-RJ, sobre a questão do voto útil no Rio e da relação religião e política.

[...] Nos escombros do brizolismo e germinado pelo início do garotismo nas áreas mais pobres da cidade, principalmente na zona oeste, brotou o voto útil evangélico. A votação de Marcelo Crivella sobrepuja o percentual eleitoral da Igreja Universal, abarca o restante do universo pentecostal e o da Igreja Batista, também forte na zona oeste, assim como alguns subúrbios como o da Central e Leopoldina. Não significa que todos os evangélicos votaram em Crivella ou que todos os católicos escolheram Cesar Maia. O insucesso da manobra política que transformou o Pastor Manoel Ferreira, da Assembleia de Deus no vice de Conde (PMDB) ${ }^{24}$, candidato do Garotinho. Os féis da não ligaram para o acordo político e aderiram a Crivella. A política passou a instrumentalizar a religião. O palanque foi ao púlpito. O reverso da medalha não tardou. Pentecostais da IURD resolveram dispensar intermediários e passaram a instrumentalizar a política em seu proveito. ${ }^{25}$

Em 2006, Crivella se candidatou ao governo do Estado do Rio, mas sem sucesso. Em 2008, apresentou-se novamente à disputa da Prefeitura do município do Rio de Janeiro na coligação "Vamos arrumar o Rio", formada pelos partidos PRB, PRTB, PR, PSDC, ficando em terceiro lugar - obteve $19 \%$ dos votos, percentual ligeiramente inferior ao de 2004, que foi de $21,8 \%$. A distribuição dos votos foi muito semelhante à da eleição anterior: os seus melhores percentuais ocorreram em bairros da Zona Oeste, Central do Brasil e Leopoldina, áreas da cidade onde a presença de evangélicos é mais expressiva. Nessa eleição, o número de votos em Crivella cresceu apenas em alguns bairros populares, como Santa Cruz, Vila Kennedy e Olaria. ${ }^{26}$

\footnotetext{
${ }^{24}$ Os candidatos mais votados à PMRJ em 2004 eram Cesar Epitácio Maia (PFL), vice Otávio Santos Silva Leite (PSDB); Marcelo Bezerra Crivella (PL), vice: Káthia Mattos Kozlowski, vice: Káthia Mattos Kozlowski; Luiz Paulo Fernandez Conde (PMDB), vice Pastor Manoel Ferreira (PP).

${ }^{25}$ TABAK, Israel. Jornal do Brasil, 10/10/2004.

${ }^{26}$ JACOB, César R., HEES, Dora R., WANIEZ, Philippe. A geografia do voto nas eleições para prefeito e presidente nas cidades do Rio de Janeiro e São Paulo: 1996-2010: Editora PUC-Rio. (http://www.editora.vrc.pucrio.br/media/Ebook_Geografia_do_voto_Rio_SaoPaulo_final.pdf)
} 
Já bastante conhecido no meio político, em 2014, Crivella se reapresentou como candidato ao governo do Estado do Rio de Janeiro, classificando-se em segundo lugar. Luiz Pezão (PMDB) obteve 40,57\% dos votos válidos, Crivella, 20,26\% e Garotinho, 19,73\%. O bispo foi para o segundo turno, e, apesar de ter sido derrotado por Pezão, obteve 44,22\% dos votos. Mas foi em 2016 que Crivella atingiu a vitória mais expressiva em sua trajetória política: governar a segunda maior cidade do país! Sem se registrar como bispo no TER - Tribunal Regional Eleitoral, venceu no segundo turno o candidato Marcelo Freixo, do PSOL, com 59,36\% dos votos, e será o prefeito carioca durante os próximos quatro anos. A campanha foi marcada por muitas dúvidas em relação à preocupação de muitos eleitores do Rio de Janeiro quanto ao significado da vinculação religiosa do prefeito eleito.

Com relação à temática revelou um deputado do PRB:

\footnotetext{
“Não é porque ele é evangélico que vai ter um governo pautado na igreja. Não tem isso.” A declaração do $1^{0}$ secretário da Câmara dos Deputados, deputado Beto Mansur (PRB-SP), correligionário do novo prefeito do Rio de Janeiro, Marcelo Crivella, explica bem qual a principal preocupação com relação à futura gestão. O grande desafio será sair da sombra da Igreja Universal e contemplar também os setores em que há embate com os evangélicos. ${ }^{27}$
}

A votação mais expressiva em Crivella ocorreu nos bairros de Santa Cruz, Sepetiba e Guaratiba, seguido de Bangu e Senador Camará, Bonsucesso, Olaria e Ramos. No figura 4, podemos verificar a frequência da vitória dos dois candidatos.

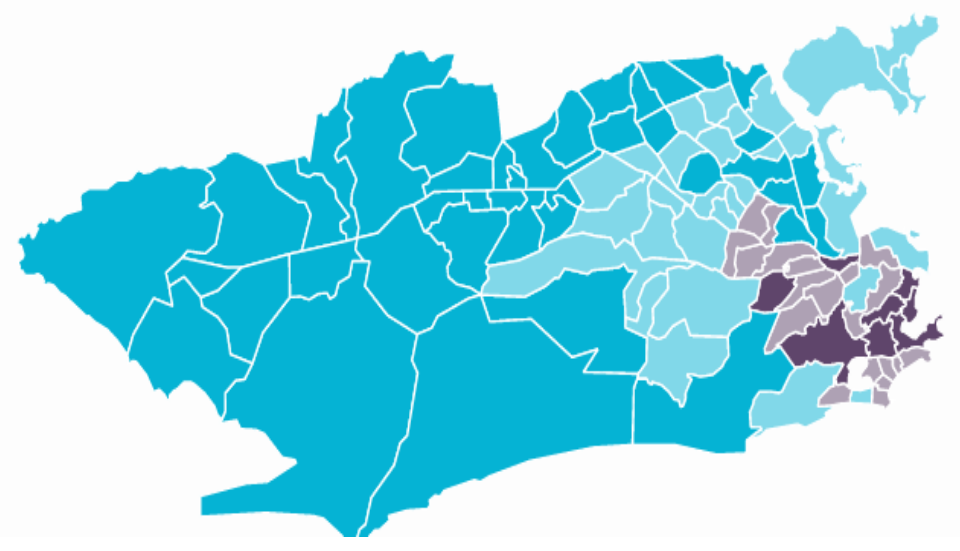

${ }^{27}$ Huffpost Brasil - http://www.brasilpost.com.br/2016/10/30/crivella-rio-de-janeiro_n_12693058.html. (Acesso em 30 de novembro de 2016) 
Figura 4. Resultado do 20 Turno - Rio de Janeiro - 2016. Fonte: http://especiais.g1.globo.com/rio-dejaneiro/eleicoes/2016/apuracao-zona-eleitoral-prefeito/rio-de-janeiro/2-turno/

Tudo indica que os líderes evangélicos planejam usar as eleições municipais de 2016 para consolidar sua força política no país. Segundo matéria veiculada na Folha de São Paulo, em setembro de 2016, "Pela primeira vez em disputas eleitorais, há uma organização de caráter nacional dando sustentação a candidaturas protestantes, pentecostais e neopentecostais.” ${ }^{28}$ Assim, expandir sua representação política no Rio de Janeiro e conseguir eleger no mínimo $60 \%$ dos candidatos evangélicos faziam parte dos objetivos da Concepab - Confederação dos Conselhos de Pastores do Brasil. Instituição que, desde 2009, reúne pastores de diferentes denominações e acompanha de perto ao menos 100 candidatos a prefeito, vice-prefeito e vereador em todo o país. Grande parte dos pastores é ligada à Igreja Universal e à Assembleia de Deus. Na avaliação da Concepab, a meta de consolidar a força política no país garantiria que, a partir de 2017, os políticos evangélicos passassem a trabalhar de maneira mais coesa, reivindicando as mesmas pautas em suas cidades, independentemente dos partidos e das igrejas às quais são vinculados. ${ }^{29} \mathrm{~A}$ vitória de Crivella no Rio, nesse sentido, pode ser mais um elemento de consolidação da união das forças evangélicas. Líderes evangélicos passaram a apostar na sua candidatura à disputa presidencial de 2018. O presidente da Confederação, o bispo Robson Rodovalho, passou a afirmar que "chegará o momento em que o Brasil terá um presidente evangélico. É natural" ${ }^{30}$

Por toda essa articulação que estamos fazendo, buscando o diálogo além de partidos e denominações, acreditamos que essas eleições serão um passo importante na conquista da representação político-partidária dos evangélicos, disse o bispo Robson Rodovalho, fundador da

\footnotetext{
${ }^{28}$ Folha de São Paulo- http://www1.folha.uol.com.br/poder/eleicoes-2016/2016/09/1814577-evangelicos-buscamatuacao-politica-mais-coesa-com-campanha.shtml. Acesso em 30 de outubro de 2016

${ }^{29}$ Folha de São Paulo - http://www1.folha.uol.com.br/poder/eleicoes-2016/2016/09/1814577-evangelicos-buscamatuacao-politica-mais-coesa-com-campanha.shtml. Acesso em 30 de outubro de 2016.

${ }^{30}$ GGN - Jornal de Todos os Brasis, coluna Luis Nassif. 01 /11/2016. http://jornalggn.com.br/noticia/evangelicosquerem-crivella-presidente-e-bancada-de-um-terco-da-camara-em-2018. Acesso em 01 de novembro de 2016.
} 
igreja Sara Nossa Terra e presidente da Concepab. Das 52 candidaturas a prefeito acompanhadas de perto pela direção nacional da Concepab, 43 são do PRB. ${ }^{31}$

Entre as candidaturas a prefeito pelo PRB nas eleições de 2016 acompanhadas pela Concebap, além de Marcelo Crivella, pelo Rio de Janeiro, que obteve êxito, esteve a de Celso Russomanno, por São Paulo, a maior e mais importante cidade brasileira. Russomanno, que é católico, era uma das principais apostas do partido; entretanto, não recebeu apoio da Concepab, em função de não contar com a simpatia do bispo Rodovalho, ficando em terceiro lugar, com 13,6\% dos votos, atrás de Fernando Haddad, do PT, com 16,7\%. João Doria, do PSDB, venceu no primeiro turno com 53,2\% dos votos.

Contudo, as disputas internas no PRB e na Confederação não se esgotaram. Embora grande parte das candidaturas apoiadas pela Concepab seja do PRB, considerado o partido mais estruturado para um trabalho de alcance nacional, é um partido muito vinculado à Iurd e à influência do bispo Edir Macedo, seu fundador, e há um movimento dos líderes que comandam essa confederação para reduzir a influência exercida por Macedo e pela própria Iurd. Disputas à parte, vale mencionar que o PRB criou, em 2007, a Fundação Republicana Brasileira (FRBr), uma instituição sem fins lucrativos mantida pelo Partido que tem como principais finalidades a pesquisa, a doutrina e a educação institucional, política e constitucional. ${ }^{32}$

Nesse sentido, é interessante observar que a Fundação tem se empenhado em subsidiar condutas para gestão municipal. Para se ter uma ideia, o Núcleo de Estudos da Fundação lançou, em junho de 2012, no Fórum Nacional, evento realizado em São Paulo, no Memorial da América Latina, com cerca de 700 participantes, a cartilha contendo os "10 Princípios para uma Gestão Pública Municipal Eficaz" para o PRB, considerados diretrizes republicanas. São eles: promoção do desenvolvimento sustentável: da qualidade de vida; da responsabilidade social; da cidadania; participação; compromisso com a busca de resultados; inovação nos arranjos organizacionais; promoção da intersetorialidade; da

\footnotetext{
${ }^{31}$ Huffpost Brasil - http://www.brasilpost.com.br/2016/10/30/crivella-rio-de-janeiro_n_12693058.html. (Acesso em 30 de novembro de 2016)

${ }^{32} \mathrm{FRBr}$ - http://fundacaorepublicana.org.br/portal/historia/. Acesso em 30 de outubro de 2016.
} 
transparência e da conexão. ${ }^{33}$ Elaborada por professores especializados em gestão pública para ser difundida por todo o Brasil, a intenção da cartilha é garantir unidade e, ao que parece, administrações competitivas e alinhadas com as novas e modernas demandas do capitalismo.

\section{Considerações finais}

Ao abordar a relação entre evangélicos, política e espaço no Brasil, achamos oportuno, inicialmente, demonstrar o crescimento desse segmento religioso no país, principalmente o pentecostal, ilustrando-o a partir de sua expressão regional. A intenção era apresentar um panorama da tendência religiosa da população brasileira e indicar que ela tem se tornado cada vez menos católica e mais evangélica. Isso ajuda a compreender, em parte, a ampliação e o fortalecimento dos evangélicos na política nacional.

Entretanto, esse fortalecimento político do segmento evangélico não é fruto apenas do seu crescimento, mas sobretudo das novas estratégias adotadas, que incluem a ampliação de suas bases em escala nacional e para além do campo religioso ou estritamente evangélico, demonstrado com a formação dos blocos políticos, fortes e coesos: as bancadas evangélicas e a Frente Parlamentar Evangélica. Se, por um lado, as pautas da Frente podem ser consideradas conservadoras, como a defesa da família tradicional, a defesa da vida desde a concepção, os direitos do nascituro, a proibição do aborto, do infanticídio, os direitos da mulher, os direitos do ente humano que está sendo gerado, por outro, suas estratégias de gestão podem ser consideradas competitivas, pragmáticas e alinhadas com as novas e modernas demandas do capitalismo.

Entre os evangélicos que têm conseguido representações partidárias e parlamentares importantes nas diversas instâncias de poder estão as igrejas Assembleia de Deus e Universal do Reino de Deus. A Assembleia de Deus é a denominação que mais cresce em número de fiéis em todo o país, já a Universal vem perdendo adeptos e diminuindo o número de filiados, com exceção da Região Nordeste,

${ }^{33} \mathrm{FTBr}$ - http://fundacaorepublicana.org.br/portal/10-principios-para-uma-gestao-publica-municipal-eficaz/. Acesso em 30 de outubro de 2016. 
que se mantém, e a Norte, que se amplia. Não obstante essa tendência de perda de adeptos, a Iurd tem se destacado no cenário político.

Assim, sem qualquer pretensão de esgotar o assunto, mas de agregar alguns elementos à investigação da influência do voto evangélico nas diferentes representações políticas no Brasil, gostaríamos de finalizar indicando que o Rio de Janeiro, que acabou de eleger como prefeito Marcelo Crivella, da Universal, pelo PRB e com apoio de vários segmentos evangélicos, passou a ocupar um espaço estratégico no rumo de Crivella à presidência da República, em 2018. Provavelmente realizará uma administração moderna, de resultados, que sirva de vitrine para levar à frente os propósitos políticos da Iurd, do PRB e dos segmentos evangélicos.

\section{REFERÊNCIAS}

Agência Pública - http://apublica.org/2016/02/truco-as-bancadas-da-camara/. Acesso em 30 de outubro de 2016.

Câmara Municipal do Rio de Janeiro - http://www.camara.rj.gov.br). Acesso em 30 de outubro de 2016.

Câmara dos Deputados (http://www2.camara.leg.br/legin/int/atomes/2005/atodamesa-69-10-novembro-2005-539350publicacaooriginal-37793-cd-mesa.html). Acesso em 18 de junho de 2016.

Câmara dos Deputados- http://www.camara.leg.br/internet/deputado/Frente_Parlamentar/53658-integra.pdf, Ata de Eleição da Frente Parlamentar Evangélica do Congresso Nacional, 2015.

Câmara dos Deputados - http://www.camara.leg.br/internet/deputado/frenteDetalhe.asp?id=53658. Acesso em 11 de novembro de 2016.

Censo Demográfico IBGE, 1980, 1991.

Censo Demográfico IBGE, 2000 e 2010. (http://www.sidra.ibge.gov.br/cd/cd2010CGP.asp?o=13\&i=P)

CUNHA, Magali. O poder evangélico no Brasil. Revista Giz, número 17, 2016. http://revistagiz.sinprosp.org.br/?p=6531. Acesso em 30 de junho de 2016.

DIAP.http://www.diap.org.br/index.php?option=com_content\&view=article\&id=14637-evangelicos-crescem-nocongresso-psc-lidera-em-numero-de-parlamentares. Acesso em 10 de maio de 2016.

El País - El País, 3 de junho de 2016

http://brasil.elpais.com/brasil/2016/06/08/opinion/1465385098_545583.html?rel=mas. Acesso 8 de agosto de 2016)

Folha de São Paulo - http://www1.folha.uol.com.br/poder/eleicoes-2016/2016/09/1814577-evangelicos-buscam-atuacaopolitica-mais-coesa-com-campanha.shtml. Acesso em 30 de outubro de 2016 
FRBr - http://fundacaorepublicana.org.br/portal/historia/. Acesso em 30 de outubro de 2016.

GGN - Jornal de Todos os Brasis, coluna Luis Nassif. 01 /11/2016. http://jornalggn.com.br/noticia/evangelicos-queremcrivella-presidente-e-bancada-de-um-terco-da-camara-em-2018. Acesso em 01 de novembro de 2016.

Grupo de Pesquisa Mídia, Religião e Política. http://www.metodista.br/midiareligiaopolitica/index.php/composicao-bancadaevangelica/ Acesso em 10 de setembro de 2016.

Huffpost Brasil - http://www.brasilpost.com.br/2016/10/30/crivella-rio-de-janeiro_n_12693058.html. Acesso em 30 de novembro de 2016.

JACOB, César R., HEES, Dora R., WANIEZ, Philippe, BRUSTLEIN, Violette. Atlas da Filiação Religiosa e Indicadores Sociais no Brasil, Rio de Janeiro: Editora PUC-Rio/ Edições Loyola, 2003.

JACOB, César R., HEES, Dora R., WANIEZ, Philippe. A geografia do voto nas eleições para prefeito e presidente nas cidades do Rio de Janeiro e São Paulo: 1996-2010: Editora PUC-Rio. (http://www.editora.vrc.puc-

rio.br/media/Ebook_Geografia_do_voto_Rio_SaoPaulo_final.pdf)

MACHADO, Mônica Sampaio. A lógica da reprodução pentecostal e sua expressão espácia. In SANTOS, M. et.alli, O novo mapa do mundo: fim de século e globalização. São Paulo: Hucitec, 1993, p.224-232.

Urbanização em tempos de Globalização, de Americanização do Mundo: algumas reflexões. In: 12 Encuentro de Geógrafos de America Latina, 2009, Montevideo. 12 Encuentro de Geógrafos de America Latina, 2009.

MACHADO, M. S.; NACIF, C. L. . A representação política dos evangélicos no Rio de Janeiro e as implicações territoriais de sua atuação no legislativo carioca. In: 11th Internacional History Society Conference - IPHS, 2004, Barcelona. 11th Conference of the International Planning History Society - IPHS. Barcelona: 11th Conference of the International Planning History Society - IPHS, 2004.

MAFRA, Clara. Os evangélicos. (2001). Rio de Janeiro: Jorge Zahar Ed.,88 p.

Noticias R7. 31 de julho de 2014. http://noticias.r7.com/brasil/com-a-presenca-de-dilma-templo-de-salomao-e-inauguradoem-sao-paulo-13102016, Acesso em 30 de agosto de 2016.

Revista Giz. http://revistagiz.sinprosp.org.br/?p=6531. Acesso em 30 de outubro de 2016.

SILVA, Magali. Entrevista de Magali Silva concedida a Elisa Marconi e Francisco Bicudo para a Revista Giz, 2016. (http://revistagiz.sinprosp.org.br/?p=6531). Acesso em 25 de junho de 2016.

ROLIM, Francisco Cartaxo. Pentecostais no Brasil: Uma Interpretação Sócio-Religiosa. Ed. Vozes, Petrópolis, 1985,260 p.

TABAK, Israel. Jornal do Brasil, 10/10/2004.

Terra, 20 de setembro de 2012 https://noticias.terra.com.br/amp/brasil/politica/prb-de-russomanno-tem-66-dos-dirigentesligados-a-universal,9cb99782ac66b310VgnCLD200000bbcceb0aRCRD.html. Acesso em 20 de outubro de 2016.

Tribunal Superior Eleitoral - http://www.tse.jus.br/eleitor/estatisticas-de-eleitorado/filiados. Acesso em 30 outubro de 2016 . 